\title{
Device Closure of Perimembranous Ventricular Septal Defect Under Deep Sedation and Transthoracic Echo Guide: A Case Report
}

\author{
NN Fatema ${ }^{1}$, H Rashid $^{2}$, AK Azad $^{3}$ \\ ${ }^{1}$ Dept. of Paediatric Carrdiology, CMH, Dhaka. ${ }^{2}$ Dept. of Carrdiology, CMH, Dhaka, ${ }^{3}$ Dept. of \\ Carrdiac Anaesthesiology, CMH, Dhaka
}

Keywords:

VSD,

Transthoracic

Echo,

Amplatzer

Device.

\begin{abstract}
:
$T$, an eight years old girl was diagnosed as a case of perimembranous Ventricular Septal Defect (VSD) since 6 months of her age. She had recurrent chest infection since early infancy. Her Echocardiography with colour Doppler showed a $4.5 \mathrm{~mm}$ perimembranous VSD which was $5 \mathrm{~mm}$ away from the aortic valve. As pulmonary artery pressure was normal, she was kept under follow up and device closure was planned. At last she was taken into the catheterization laboratory of combined military Hospital, Dhaka on $1^{\text {st }}$ July 2008 and VSD was closed with an $8 \mathrm{~mm}$ Amplatzer perimembranous VSD device. Whole procedure was done under deep sedation with Ketamine and transthoracic echocardiography (TTE) and fluroscopy guide. It is the first ever case of VSD device closure where procedure was done under sedation and TTE guide which lead to the writing of this report.
\end{abstract}

(Cardiovasc. j. 2010; 3(1): 89-91)

\section{Introduction:}

Ventricular Septal Defect (VSD) is the most commonly encountered congenital lesion reported in most cardiac centers. ${ }^{1}$ It accounts for $35 \%$ of all congenital heart lesions in Bristol Seris. ${ }^{2}$ The incidence of VSD in all live birth is approximately 1.5 to 3.5 per 1000 term infants and 4.5 to 7 per thousands premature infants. ${ }^{3,4}$ Surgical closure of haemodynamically significant VSD's has long been established worldwide. Device closure of VSD is less well accepted and can only be regarded as an option for very selected cases, and available in a small number of centres worldwide. ${ }^{5,6}$ This procedure is complicated, needs presence of at least three cardiologists for smooth running of the operation. One cardiologist and two cath lab nurse had performed this case under the guide of transthoracic echo and fluoroscopy. Deep sedation with Ketamine was given. An Anaesthesiologist was kept ready for giving general aneasthesia at the time of requirement but it was not needed at all.

\section{Case Report:}

Miss T, an eight years old girl was diagnosed as a case of perimembranous VSD since 6 months of her age. She had history of repeated hospital admission with respiratory tract infection. Initially VSD was large and it was $7 \mathrm{~mm}$ in size. On her subsequent follow up size of VSD gradually reduced. She had mild degree of growth failure also. Her pulmonary artery systolic pressure was

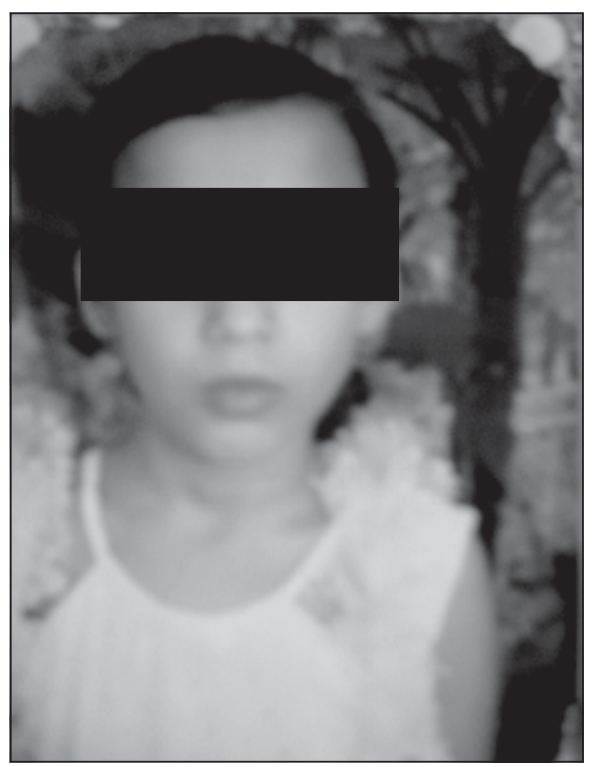

Fig-1: Miss T, first ever case of VSD device closure performed in Bangladesh under Transthoracic echo guide and deep sedation. 
40-45 mm Hg in $1^{\text {st }}$ few follow up. She was treated initially with Frusemide, Digoxin and Captopril. Subsequently her pulmonary artery pressure returned to normal with reduction of size of VSD. In her follow up on April 2005 Chest X-ray showed mild cardiomegaly and ECG was normal for age. VSD size in color Doppler echocardiography was $4.5 \mathrm{~mm}$. Her pulmonary artery pressure was calculated as $30 \mathrm{mmHg}$. Distance of aortic valve from VSD margin was $5 \mathrm{~mm}$. She was planned for device closure. She was taken into cath lab on $1^{\text {st }}$ July 2008. She was sedated with injection Ketamine and injection Midazolam during procedure. Induction of general anaesthesia at any moment was assured.

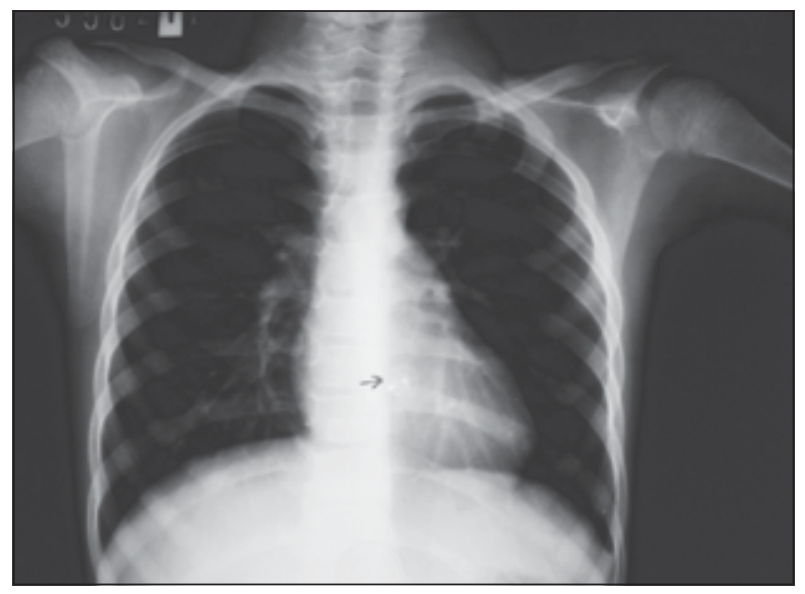

Fig- 2: Chest X-ray showing PM VSD Device

\section{Equipments required:}

1. AMPLATZER Perimembranous VSD device 8 $\mathrm{mm}$ size in the waist.

2. Torque delivery system.

3. Terumo exchange wire.

4. Arterial and venous sheath.

5 Judkin's Right (JR) catheter.

6. Pigtail catheter.

7. Snare catheter.

8. Berman balloon Angiographic catheter.

9. Standard paediatric drape.

10. Echocardiography machine.

\section{Procedure:}

A 5 French ( $\mathrm{Fr}$ ) sheath was introduced to right femoral vein (RFV). A 5 Fr sheath was introduced to right femoral artery (RFA) and $4 \mathrm{Fr}$ sheath to left femoral artery (LFA). A pigtail left ventriculography was done to locate VSD and to measure its distance from aortic valve. A JR-4 catheter was introduced through RFA and VSD was crossed easily with Terumo wire. Terumo wire was exchanged with long exchange wire and it was snared from main pulmonary artery. Exchange wire was taken out of the body through RFV in such a way that a loop was formed with exchange wire all the way from RFA through left and right ventricle and then it came out through RFV. A torque delivery system was than introduced through RFV to aortic root and it was then dropped to LV in such a way that tip of sheath should points towards LV apex. Perimembranous VSD device was than loaded to loader with the help of delivery cable and pusher catheter. Loader was than connected to delivery sheath carefully to avoid air bubbles. Whole system was than forwarded through delivery sheath to LV. LV disc was released under transthoracic and fluoroscopy guide. Whole system was withdrawn carefully and RV disc was released. Patient was discharged from hospital 72 hours after procedure with follow up appointment at 1 , $3,6,9,12,18,24$ months and yearly thereafter for three years.

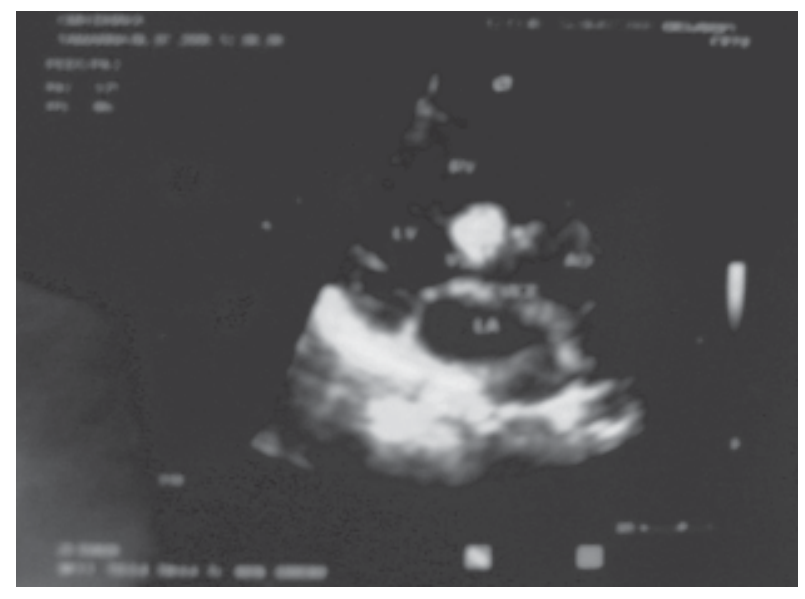

Fig-3: Echo of the patient showing VSD device in position.

\section{Discussion:}

The procedure for percutaneous closure of VSD with intracardiac device was first attempted by lock et al in 1988 and originally designed devices were used with a variable success rate. ${ }^{6,7}$ Device option used for VSD closure were Rashkind device, VSD OS, Amplatzer VSD device and cardio seal. The Amplatzer VSD occluder has been undergoing clinical trial since 1988 after the animal 
experiments had shown $100 \%$ occlusion and complete endothelization at three months. ${ }^{8}$ In 2002, Hijazi et al reported the initial human use in six patients with complete closure in all and the absence of any significant complications. In this case we use Amplatzer PM VSD occluder of $8 \mathrm{~mm}$ size in the waist and $14 \mathrm{~mm}$ and $12 \mathrm{~mm}$ on LV and RV side respectively. A study was conducted in Asabu University, Japan where coil was used for closing VSD's in dogs. They concluded that trans catheter closure of small perimembranous VSD with detachable coil can be performed without major complications. ${ }^{9}$ A study conducted in Brazil proved that percutaneous closure of perimembranous VSD with Amplatzer occluder is safe, feasible and effective. ${ }^{10}$ This study concluded that Amplatzer PM VSD occluder was suitable to close a wide range of perimembranous VSD with various size and morphologies with good short term outcomes. In this case we used Amplatzer PM VSD occluder. This device is used in several center of the world now with good short term outcomes. It will need some time to get long term outcomes of these cases. In our center first case of perimembranous VSD was performed in August 2004. All the cases (20) performed since then are doing very well. No complications are encountered yet in follow up of these cases.

\section{Conclusion:}

VSD device closure procedure still remains challenging and controversial. However, there are a small group of children with VSD's that are difficult to close surgically and involve substantially higher risk. These defects can be closed with devices. Many patients, specially females do not want any scar in the chest. Those cases can be done if there is no associated problems like aortic valve prolapse, infundibular stenosis etc. Surgically inaccessible VSD and multiple VSD's is good candidate for device. Hybrid procedure for closing VSD is now practiced in many center of the world, where surgeon do thoracotomy and paediatric cardiologist introduce device by directly cannulating heart. In our center we prefer device closure if the candidate fulfilled the criteria for it completely.

Financial Disclosure - None

\section{References:}

1. Thomas PG MD, Harverd PG MD. Ventricular Septal Defects In: GC Emmanouilides, Hugh D Allen, Thomas A. Riemenschnieder, Harverd P. Gutgessel eds. Moss and Adams Heart disease in Infant children and adolescent. $5^{\text {th }}$ ed. Baltimone: Williams and Willkins, 1995. PP 724- 746.

2. Hoffman JLE, Rudloph AM. The natural history of ventricular septal defect in infancy. Am J cardiol 1965; 16: 634-653.

3. Moe DG, Guntheroth WG. Spontaneous closure of uncomplicated ventricular septal defect. Am J cardiol 1987; 60: 634-653.

4. Sommer RJ, Golinko RJ, Ritter SB. Intracardiac shunting in children with ventricular septal defect: evaluation with Doppler colour flow mapping. $J$ Am Coll Cardiol 1990; 16: 1687-1695.

5. King TD, Mill NL. Non operative closure of Atrial septal defect. Surgery 1994; 75: 383-388.

6. Arora R, Trehan V, Thakur AK, Mehta V, Sengupta PP, Vigons M.Transcatheter closure of Muscular Ventricular Septal defects. J Interv Cardiol 2004; 17 (20): 109-115.

7. Wilkinson JL. Interventional paediatric cardiology: Device closure. Indian J Pediats 2000; 67 (7): 507-513.

8. Holzer R, Blarer D, Amin Z, Ruiz CE, Feirstein J. Closure of post infarction ventricular septal defects using the new Amplatzer muscular VSD occluded; Result of a US registry. Catheter Cardiovasc Interv 2004;61(2):196201.

9. Fujii Y, Fukuda T, Machida N, Yamane T, Wakas Y. Trans catheter closure of congenital ventricular septal defect in 3 dogs with detachable coil. $J$ Vet intern Med 2004; 18 (6): 911-914.

10. Pedra CA, Pedra SR, Esteves CA, Pontes SC Jr, Braga SL, Arriea SR et al. Percutaneous closure of ventricular septal defect: Technical and morphological consideration. Catheter Cardivasc Interv 2004; 61 (3): 403-410. 